\title{
A review of down-hole tubular string buckling in well engineering
}

\author{
De-Li Gao ${ }^{1}$ - Wen-Jun Huang ${ }^{1}$
}

Received: 15 May 2015/Published online: 24 July 2015

(c) The Author(s) 2015. This article is published with open access at Springerlink.com

\begin{abstract}
Down-hole tubular string buckling is the most classic and complex part of tubular string mechanics in well engineering. Studies of down-hole tubular string buckling not only have theoretical significance in revealing the buckling mechanism but also have prominent practical value in design and control of tubular strings. In this review, the basic principles and applicable scope of three classic research methods (the beam-column model, buckling differential equation, and energy method) are introduced. The critical buckling loads and the post-buckling behavior under different buckling modes in vertical, inclined, horizontal, and curved wellbores from different researchers are presented and compared. The current understanding of the effects of torque, boundary conditions, friction force, and connectors on down-hole tubular string buckling is illustrated. Meanwhile, some unsolved problems and controversial conclusions are discussed. Future research should be focused on sophisticated description of buckling behavior and the coupling effect of multiple factors. In addition, active control of down-hole tubular string buckling behavior needs some attention urgently.
\end{abstract}

Keywords Down-hole tubular mechanics - Tubular string buckling - Wellbore configuration - Boundary condition . Friction force

De-Li Gao

gaodeli@cast.org.cn; huangwenjun1986@126.com

1 MOE Key Laboratory of Petroleum Engineering, China University of Petroleum, Beijing 102249, China

Edited by Yan-Hua Sun

\section{Introduction}

Tubular string buckling is an important issue in well engineering. Buckling makes the initially straight tubular string buckle into curved shapes, which is an important reason for the well deviation problem. Buckling can also increase both bending stress on the tubular string and the contact force between the tubular string and the wellbore, which may further lead to serious down-hole problems such as tubular string failure, casing wear, hard slack off, or even "lock up." Down-hole tubular string buckling is usually taken as analogous to the Euler buckling problem for a rod with axial compressive forces on both ends. The rod remains straight until the axial force exceeds a certain value, namely the critical load. When the axial force is larger than the critical value, the initial configuration becomes unstable and the rod buckles into a laterally deformed configuration. However, unlike the free postbuckling deflection of the Euler rod, various external factors, such as the constraint of wellbore, tubular string weight, torque, friction force, etc., make tubular string buckling behavior more complex.

The first systematic research on tubular string buckling was conducted by Lubinski (1950). His pioneering work revealed the buckling mechanism of rotary drill strings in vertical wellbores and gave the critical buckling condition and post-buckling behavior of the drill string. Since then, a lot of improvement has been made in theoretical models and experiments. Many tubular string buckling models in vertical, horizontal, inclined, and curved wellbores under the action of torque, boundary condition, friction force, connectors, etc. have been proposed, some of which have been verified in later experiments and actual engineering operations. Despite all these achievements, some problems remain and need to be solved. For example, there is no 
accurate model so far to depict the transition process from two-dimensional lateral buckling to three-dimensional buckling in vertical wellbores. Different researchers derive inconsistent results of critical helical buckling loads for slightly inclined wellbores, for the transition process from sinusoidal buckling to helical buckling is a rather complex phenomenon and different researchers have adopted different assumptions. The studies of the effects of friction force, connectors, etc. are not mature and lack in-depth and systematic work.

In this paper, we review the progress in down-hole tubular string buckling. Classical research methods about down-hole tubular string buckling are presented. The effects of wellbore configuration, torque, boundary condition, friction force, connectors on tubular string buckling are discussed. Meanwhile, comments on some unsolved problems and controversial conclusions are presented.

\section{Research methods}

\subsection{Beam-column model}

Because the lateral displacement of the tubular string in wellbores is much smaller than the axial length, the linear elastic theory based on a small displacement is satisfied. The governing equation of tubular string buckling can be expressed by linear differential equations with respect to lateral displacements. When the tubular string does not contact the borehole wall or is in contact with the well wall at several single points, the distributed force on the downhole tubular string is equal to tubular string weight and the governing equation for a inclined straight wellbore is expressed as follows (Gao 2006; Gao and Liu 2013):

$$
\left\{\begin{array}{l}
\frac{\mathrm{d}^{4} u}{\mathrm{~d} z^{4}}+\frac{M_{\mathrm{T}}}{E I} \frac{\mathrm{d}^{3} v}{\mathrm{~d} z^{3}}+\frac{\mathrm{d}}{\mathrm{d} z}\left(\frac{F-q z \cos \alpha \mathrm{d} u}{E I}\right)-\frac{q \sin \alpha}{E I}=0 \\
\frac{\mathrm{d}^{4} v}{\mathrm{~d} z^{4}}-\frac{M_{\mathrm{T}}}{E I} \frac{\mathrm{d}^{3} u}{\mathrm{~d} z^{3}}+\frac{\mathrm{d}}{\mathrm{d} z}\left(\frac{F-q z \cos \alpha \mathrm{d} v}{E I} \frac{\mathrm{d} z}{\mathrm{~d} z}\right)=0
\end{array},\right.
$$

where $u$ and $v$ are the lateral displacements along $x$ and $y$ coordinates, respectively; $z$ is the axial distance; $F$ is the axial compressive force at the bottom end; $M_{\mathrm{T}}$ is the torque; $E I$ is the bending stiffness; $q$ is the weight per unit length of the down-hole tubular string; $\alpha$ is the hole angle.

The general solution of Eq. (1) can be expressed as the linear combination of certain linearly independent functions, namely

$w=\mathbf{G}^{\mathrm{T}} \mathbf{X}+w_{\mathrm{g}}$,

where $w$ is the lateral displacement ( $u$ or $v$ ); $\mathbf{X}$ is the vector of undetermined constants and $\mathbf{G}$ is the vector of linearly independent power series with respect to the variable; $w_{\mathrm{g}}$ is the lateral displacement caused by lateral tubular string weight (namely $q \sin \alpha$ ). With the general solution Eq. (2), the differential equation problem for down-hole tubular string buckling can be converted to an algebraic equation problem, which significantly reduces the complexity of the tubular string buckling problem.

The beam-column model has been applied to lateral buckling of a drill string under a zero-torque condition in vertical wellbores $\left(\alpha=0\right.$ and $M_{\mathrm{T}}=0$ ) (Lubinski 1950). According to Lubinski's analysis, a system of linear equations in the form of $\mathbf{M X}=0$ is obtained by substituting the general solution Eq. (2) into boundary conditions at the top and bottom ends of the drill string. The critical lateral buckling force is obtained when $\mathbf{X}$ is not a zero vector, namely the determinant of the coefficient matrix $\mathbf{M}$ is equal to zero.

Generally, the beam-column model is used to depict the suspended section for the down-hole tubular string with multiple connectors distributed discretely (Mitchell 1982, 2000, 2003a; Huang and Gao 2014a,b, 2015). The suspended section between two adjacent connectors is usually very short, so the axial force on every suspended section can be approximately taken as a constant. Hence, the vector $\mathbf{G}$ in Eq. (2) can be written in a simpler form (Timoshenko and Gere 1963):

$\mathbf{G}=\left[\begin{array}{llll}1 & z & \sin (\sqrt{F / E I} \cdot z) & \cos (\sqrt{F / E I} \cdot z)\end{array}\right]^{\mathrm{T}}$.

Every suspended section is depicted by the above general solution and the terms including the lateral displacement, tangent direction, bending moment, and tangent shear force are all continuous at the connecting points between every two adjacent suspended sections. Introducing the boundary conditions at the ends of the integral tubular string, a system of nonlinear algebraic equations can be obtained. In this way, the down-hole tubular string buckling problem is transformed into the properties of the solutions of the nonlinear algebraic equations.

\subsection{Buckling differential equation}

For most cases, the down-hole tubular string is in continuous contact with the wellbore. The distributed force on the tubular string is equal to the sum of tubular string weight and the contact force between the tubular string and the wellbore. By introducing the wellbore constraint equations $u=r_{\mathrm{c}} \cos \theta$ and $v=r_{\mathrm{c}} \sin \theta$, the governing equation is transformed into the following differential equation form (Gao 2006):

$$
\begin{array}{r}
\frac{\mathrm{d}^{4} \theta}{\mathrm{d} z^{4}}-6\left(\frac{\mathrm{d} \theta}{\mathrm{d} z}\right)^{2} \frac{\mathrm{d}^{2} \theta}{\mathrm{d} z^{2}}+3 \frac{M_{\mathrm{T}}}{E I} \frac{\mathrm{d} \theta}{\mathrm{d} z} \frac{\mathrm{d}^{2} \theta}{\mathrm{d} z^{2}}+ \\
\frac{\mathrm{d}}{\mathrm{d} z}\left(\frac{F}{E I} \frac{\mathrm{d} \theta}{\mathrm{d} z}\right)+\frac{q \sin \alpha}{E I r_{\mathrm{c}}} \sin \theta=0
\end{array}
$$


and the contact force on the tubular string is calculated by the the following equation:

$N=E I r_{\mathrm{c}}\left[4 \frac{\mathrm{d}^{3} \theta}{\mathrm{d} z^{3}} \frac{\mathrm{d} \theta}{\mathrm{d} z}+3\left(\frac{\mathrm{d}^{2} \theta}{\mathrm{d} z^{2}}\right)^{2}-\left(\frac{\mathrm{d} \theta}{\mathrm{d} z}\right)^{4}\right]+$

$M_{\mathrm{T}} r_{\mathrm{c}}\left[\left(\frac{\mathrm{d} \theta}{\mathrm{d} z}\right)^{3}-\frac{\mathrm{d}^{3} \theta}{\mathrm{d} z^{3}}\right]+F r_{\mathrm{c}}\left(\frac{\mathrm{d} \theta}{\mathrm{d} z}\right)^{2}+q \sin \alpha \cos \theta$,

where $\theta$ is the angular displacement shown in Fig. $1 ; r_{\mathrm{c}}$ is the radial clearance between the tubular string and the wellbore; $N$ is the compressive contact force on the tubular string per unit length.

Different from the beam-column model expressed by two variables $u$ and $v$, there is only one variable $\theta$ in the buckling differential equation. However, it is difficult to solve the buckling differential equation due to the existence of nonlinear terms. If the friction force is introduced, the axial force $F$ is related to the contact force $N$, and the complexity of the buckling differential equation is increased a lot. Up to now, general analytical solutions for the buckling differential equation Eq. (4) have not been found. Sinusoidal buckling and helical buckling are considered to be two representative solutions for Eq. (4) at present. It is generally accepted that a long tubular string constrained in a wellbore goes through an initial straight configuration, then sinusoidal buckling and later helical buckling with an increase in the axial compressive force from zero. These two buckling modes have been observed in a lot of experiments.

Sinusoidal buckling means that the tubular string behaves like a snaking curve along the lower side of the inclined wellbore. The sinusoidal buckling solution is usually expressed by

$\theta=A \sin (\omega \cdot z)$,

where $A$ is the amplitude and $\omega$ is the angular velocity of the angular displacement fluctuation. The critical load $F_{\text {crs }}$ for the sinusoidal buckling can be obtained by analyzing

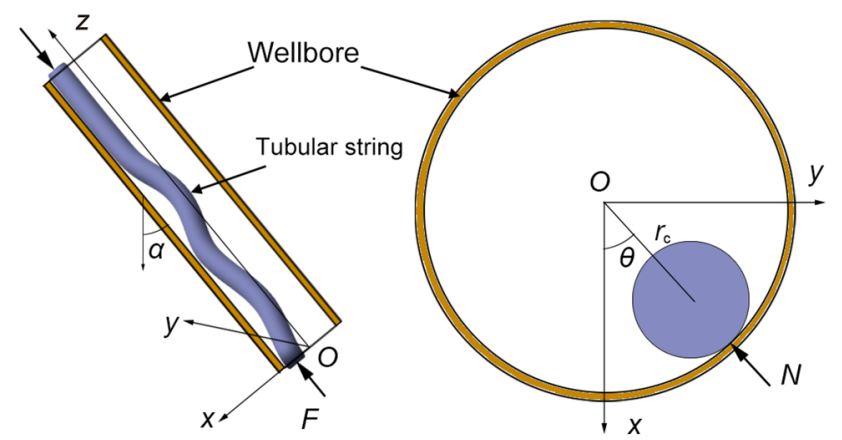

(a) Side review

(b) Cross section

Fig. 1 Down-hole tubular string buckling in a inclined straight wellbore the stability of the approximate linear form of Eq. (4) (Gao et al. 1998; Gao and Miska 2009). The relationship between the amplitude $A$ and the axial force $F$ is calculated by solving Eq. (4) with a perturbation method (Gao and Miska 2009).

Helical buckling means that the down-hole tubular string becomes a helix which spirals around the inner surface of the wellbore. The helical buckling solution can be expressed as follows:

$\theta=\frac{2 \pi}{p} z \quad$ or $\quad \theta=\frac{2 \pi}{p} z+A \sin \left(\frac{2 \pi}{p} z\right)$,

where $p$ is the helix pitch; $A$ is the fluctuation amplitude caused by the tubular string weight. The analytical solution for the parameter $p=2 \pi \sqrt{2 E I / F}$ is deduced from Eq. (4) for a weightless tubular string without torque (Mitchell 1988; Gao 2006). The parameter $A$ is approximately solved with the perturbation method by assuming $A$ to be a small term (Liu 1999; Gao and Miska 2010a). The critical load $F_{\text {crh }}$ which converts the sinusoidal buckling to helical buckling is obtained when the contact force $N$ between the tubular string and the high side of the inclined wellbore is equal to zero (Liu 1999).

\subsection{Energy method}

The energy method is another effective tool for us to study down-hole tubular string buckling problems. Compared to approximate solutions Eqs. (6) and (7) directly from the buckling differential equation, the buckling solutions from the energy method can be assumed more freely to depict the buckling configuration. Substituting approximate solutions such as Eqs. (6) or (7) into the total potential energy expression and calculating its minimum value, the buckling solutions can be determined. Meanwhile, the energy method is better used to calculate the critical buckling load and to analyze the stability of the postbuckling configuration.

For the suspended section on which the tubular string is not in contact with the wellbore, the total potential energy of the tubular string in inclined wellbores is expressed as the function of lateral displacements (Gao 2006):

$$
\begin{aligned}
& \Pi=U_{\mathrm{b}}-\Omega_{\mathrm{F}}-\Omega_{\mathrm{M}}-\Omega_{\mathrm{q}} \\
& =\frac{1}{2} \int_{z=0}^{L}\left\{E I\left[\left(\frac{\partial^{2} u}{\partial z^{2}}\right)^{2}+\left(\frac{\partial^{2} v}{\partial z^{2}}\right)^{2}\right]-F\left[\left(\frac{\partial u}{\partial z}\right)^{2}+\left(\frac{\partial v}{\partial z}\right)^{2}\right]\right. \\
& \left.-M_{\mathrm{T}}\left[\frac{\partial u}{\partial z} \frac{\partial^{2} v}{\partial z^{2}}+\frac{\partial v}{\partial z} \frac{\partial^{2} u}{\partial z^{2}}\right]+2 q \sin \alpha\left(r_{\mathrm{c}}-u\right)\right\} \mathrm{d} z .
\end{aligned}
$$

For the continuous contact section on which the the tubular string is in continuous contact with the wellbore, 
the total potential energy is expressed as the function of angular displacement:

$$
\begin{aligned}
\Pi= & \frac{1}{2} r_{\mathrm{c}}^{2} \int_{z=0}^{L}\left\{E I\left[\left(\frac{\mathrm{d} \theta}{\mathrm{d} z}\right)^{4}+\left(\frac{\mathrm{d}^{2} \theta}{\mathrm{d} z^{2}}\right)^{2}\right]-F\left(\frac{\mathrm{d} \theta}{\mathrm{d} z}\right)^{2}\right. \\
& \left.-M_{\mathrm{T}}\left(\frac{\mathrm{d} \theta}{\mathrm{d} z}\right)^{3}+\frac{2 q \sin \alpha(1-\cos \theta)}{r_{\mathrm{c}}}\right\} \mathrm{d} z,
\end{aligned}
$$

where $U_{\mathrm{b}}$ is the elastic bending energy; $\Omega_{\mathrm{F}}$ is the virtual work for axial force; $\Omega_{\mathrm{M}}$ is the virtual work for torque; and $\Omega_{\mathrm{q}}$ is the virtual work for tubular string weight.

To be specific, the amplitude $A$ for sinusoidal buckling is calculated by introducing $\theta=A \sin (\omega \cdot z)$ into the total potential energy equation for the continuous section and letting the total energy reach the minimum value $\frac{\partial \Pi}{\partial A}=0$. With the critical stability condition $\frac{\partial^{2} \Pi}{\partial A^{2}}=0$, the critical load $F_{\text {crs }}$ is obtained (Liu 1999; Gao and Miska 2009), which converts the initial straight configuration into sinusoidal buckling. Similar to the analysis in sinusoidal buckling, the helical buckling pitch $p$ for a weightless tubular string is deduced by introducing $\theta=\frac{2 \pi}{p} z$ into Eq. (9) and letting $\frac{\partial \Pi}{\partial p}=0$ (Lubinski and Althouse 1962). For a tubular string with weight, the helical buckling solution is $\theta=\frac{2 \pi}{p} z+A \sin \left(\frac{2 \pi}{p} z\right)$, which is more complicated than that for the weightless tubular string, whereas the solution process for the helical buckling fluctuation amplitude $A$ is similar. Different from the stability criterion for sinusoidal buckling, the critical force $F_{\text {crs }}$ which converts sinusoidal buckling to helical buckling is deduced by letting $\Delta \Pi=0$, where $\Delta \Pi$ means the difference of total potential energy at the helical buckling and the initial configuration stages (Chen et al. 1990; Wu 1992; Cunha 1995).

However, the above three research methods are usually not isolated from each other. The combination of the three methods can give a sophisticated description of the tubular string deflection. For example, in the derivation of the deflection curve on the transition section near the boundary, the beam-column model is used to depict the suspended section while the buckling differential equation to depict the perturbed buckling section (Sorenson and Cheatham 1986; Liu et al. 1999). Taking a down-hole tubular string with two connectors on its two ends as another example, the two portions of the tubular string near the connectors are suspended, while the middle portion is in continuous contact with the wellbore. Similar to the analysis about boundary conditions, the suspended section and the continuous contact section are, respectively, depicted by the beam-column model and the bucking differential equation. In addition, the relative angular displacement between the two connectors is obtained when the total potential energy of the down-hole tubular string achieves the minimum value (Huang and Gao 2014b). However, it is not an easy task for the simultaneous applications of the three classic methods because of the complicated solution process of the nonlinear algebraic equation systems.

\section{Effect of wellbore configuration}

\subsection{Vertical wellbore}

The critical buckling load for a tubular string in a vertical wellbore is an important issue. Lubinski (1950) studied the two-dimensional lateral buckling problem with the beamcolumn model and gave the critical buckling forces for the lowest two modes of buckling solutions shown in Table 1 . When the axial force on the bottom of the tubular string reaches the first critical force, the initially straight tubular string becomes unstable and buckles into a two-dimensional curve with only a first order vibration. The curved configuration of the tubular string is believed to be one important reason for well deviation. When the axial force increases further and exceeds the second critical value, the tubular string deflection curve is seen as a second order vibration function and the tubular string tends to touch the inner surface of the wellbore on both sides of the wellbore axis. However, the tubular string does not sequentially buckle in a higher order of two-dimensional lateral buckling but becomes a three-dimensional curve with the increase in the axial force. Lubinski and Althouse (1962) assumed the three-dimensional curve to be a helix and deduced the pitch-force relationship with the energy method:

$F=\frac{8 \pi^{2} E I}{p^{2}}$.

Although Eq. (10) is derived for a weightless tubular string, it is proved to be an effective approximation for a tubular string with weight (Gao et al. 1996). The contact force between the helically buckling tubular string and the wellbore is equal to (Mitchell 1988)

$N=\frac{F r_{\mathrm{c}}^{2}}{4 E I}$.

At first, the critical load which initiates helical buckling in vertical wellbores is approximately considered to be 0 $(F=0)$ for a tubular string with rather small bending stiffness, such as tubing. As a result, the down-hole tubular string deflection is divided into two parts with the neutral point $(F=0)$ as the dividing point: the initial straight configuration above the dividing point and a full helix 
Table 1 The critical buckling loads for vertical wellbores

\begin{tabular}{llll}
\hline Buckling mode & Lateral buckling & Sinusoidal buckling & Helical buckling \\
\hline Dimensionless force $\left(\sqrt[3]{E I q^{2}}\right)$ & 1.94 and 3.75 (Lubinski 1950) & $2.55(\mathrm{Wu}$ 1992) & 0.00 (Lubinski and Althouse 1962) \\
& & & 5.55 (Wu 1992) \\
& & 5.62 (Gao 2006) \\
\hline
\end{tabular}

depicted by Eq. (10) below the dividing point. Later, it was realized that it is too conservative to take the neutral point as the critical helical buckling force for the drill string. Wu (1992) improved the calculation method for the critical force between the three-dimensional sinusoidal buckling and helical buckling in vertical wellbores with the energy method shown in Table 1. In Wu's analysis, the tubular string buckles into a half-sine wave under the critical sinusoidal buckling condition and into a pitch of helix under the critical helical buckling condition.

Gao et al. (2002) and Gao (2006) pointed out that the sinusoidal buckling is unstable but helical buckling is stable in vertical wellbores with energy stability analysis and deduced the critical helical buckling with the buckling differential equation by letting the contact compressive force be positive for a period of the helix. Although different methods are employed in Wu's and Gao's research, their results for the critical helical buckling force are close to each other.

Mitchell (1988) studied helical buckling by solving the buckling differential equation numerically and proved that Lubinski's helical buckling model (Lubinski and Althouse 1962) was just an approximate result. Mitchell's results show that the pitch-force relationship expressed in Eq. (10) becomes invalid to depict the tubular buckling behavior near the neutral point because the tubular string may be not in contact with the wellbore.

Previous studies indicate that a key but tough problem is the depiction of the transition between the top suspended section and the bottom helically buckled section. A comprehensive model should consider the two sections as a whole: the top suspended section is depicted by the beamcolumn model and the bottom continuous contact section is depicted by the buckling differential equation. As a result, the dividing point can be determined with continuity conditions of axial displacement, slopes, bending moments and shear contact force of the two sections. In addition, how the two-dimensional lateral buckling turns to three-dimensional helical buckling with an increase in axial force has not been accurately described until now. A model for depicting the whole transition process of buckling state from initial vertical configuration, two-dimensional lateral buckling to the final helical buckling should be proposed.

\subsection{Straight inclined and horizontal wellbores}

Different from the vertical wellbores, the tubular string bucking behavior is greatly affected by the component of the tubular string weight perpendicular to the wellbore axis. If there is no axial force applied, the straight tubular string lies on the lower side of the wellbore. With the axial compression increasing to a certain value, the tubular string moves up from the wellbore bottom and buckles into a certain configuration. During this process, the axial force, which makes the tubular string become unstable, contends with other stable factors such as the wellbore constraint, perpendicular weight component, and the bending stiffness of the tubular string. That is to say, the buckling state is a comprehensive function of the stable and unstable factors.

Paslay and Bogy (1964) first introduced a trigonometric series to represent the buckling shape of the tubular string and obtained the critical sinusoidal buckling load for a long tubular string in an inclined wellbore with the energy method:

$F_{\mathrm{crs}}=\frac{E \operatorname{In}^{2} \pi^{2}}{L^{2}}+\frac{L^{2} q \sin \alpha}{n^{2} \pi^{2} r_{\mathrm{c}}}$,

where $L$ is the tubular length, $n$ is the number of half-period sinusoidal curves, $q$ is the tubular string weight, and $\alpha$ is the inclination angle of the wellbore, $F_{\text {crs }}$ is the critical sinusoidal buckling load. The minimum value of Eq. (12) is obtained by letting $\frac{n \pi}{L}=\left(\frac{q \sin \alpha}{E I r_{\mathrm{c}}}\right)^{\frac{1}{4}}$ (Dawson 1984),

$F_{\mathrm{crs}}=2 \sqrt{\frac{E I q \sin \alpha}{r_{\mathrm{c}}}}$

Equation (13) quantitatively depicts the critical state under the combined effects of stable and unstable factors. To simplify Paslay's derivation, a sine function buckling shape is assumed and then Eq. (13) can be directly deduced with the energy method (Chen et al. 1990; Miska et al. 1996; Liu 1999), Gao et al. (1998) obtained an identical solution with stability analyses on the approximate linear form of the buckling equation. The theoretical results are close to the Dellinger's experiments (Dellinger et al. 1983), and the fitting formulas for horizontal wellbores from the experimental data are $F_{\mathrm{crs}}=2.93 E I^{0.479} q^{0.522} r^{-0.436}$. 
After the axial force exceeds the critical value, the deflection curve of the tubular string can be approximately expressed by Eq. (6), where $A$ is the amplitude and $\omega$ is the angular velocity of the angular displacement fluctuation. Different solving methods may lead to different solutions. For example, Gao and Miska (2010a) obtained $\omega=$ $\left(\frac{q \sin \alpha}{E I r_{\mathrm{c}}}\right)^{\frac{1}{4}}, A=4 \sqrt{\frac{\beta-1}{11}}$ and $\beta=\frac{F}{F_{\text {crs }}}$ by solving the buckling differential equation with the perturbation method, while Gao (2006) obtained $\omega=\sqrt{\frac{F}{2 E I}}$ and $A=\sqrt{\frac{8\left(\beta^{2}-1\right)}{12 \beta^{2}-1}}$ with the energy method. In fact, these two results are rather close to each other when the axial force approaches the critical sinusoidal buckling force $(\beta \approx 1)$.

With an increase in the axial force, the sinusoidal buckling configuration becomes unstable and then buckles into a helical configuration. Unlike the distinct critical point between the initial configuration and sinusoidal buckling, there is no theoretical model to accurately represent the transition between these two completely different buckling modes-sinusoidal buckling and helical buckling. Different researchers proposed various assumptions about the transition process and derived different forms for the critical buckling loads with the energy stability principle. The main transition processes are illustrated in Fig. 2 and the values of critical buckling loads are given in Table 2.

Chen et al. (1990) first deduced the critical force to cause helical buckling with the energy method and stated that critical helical buckling load was $\sqrt{2}$ times the critical sinusoidal buckling load. In Chen's research, the axial force on the tubular string was assumed to be constant during the process from the starting of sinusoidal buckling to helical buckling. By assuming that the axial force increases linearly from the start of sinusoidal buckling to helical buckling, Wu (1992) refined Chen's method and pointed out that Chen's result was an average value of the critical sinusoidal and helical buckling loads. According to $\mathrm{Wu}$, the critical helical buckling load is $2 \sqrt{2}-1$ times the critical sinusoidal buckling load. Miska et al. (1996) assumed that the axial force increased linearly in the entire loading process and found that the critical helical buckling load was $2 \sqrt{2}$ times the critical sinusoidal buckling load. Miska et al. (1996) also proved that the sinusoidal buckling configuration became unstable ( $\beta=1.875)$ before the tubular string changes to the helical buckling configuration. Therefore, the tubular string may be in a sinusoidal or helical buckling state when the axial force satisfies $1.875<\beta<2 \sqrt{2}$. Cunha (1995) pointed out that there are two critical helical buckling loads, where the lower limit value is equal to Chen's result and the upper limit is equal to Miska's

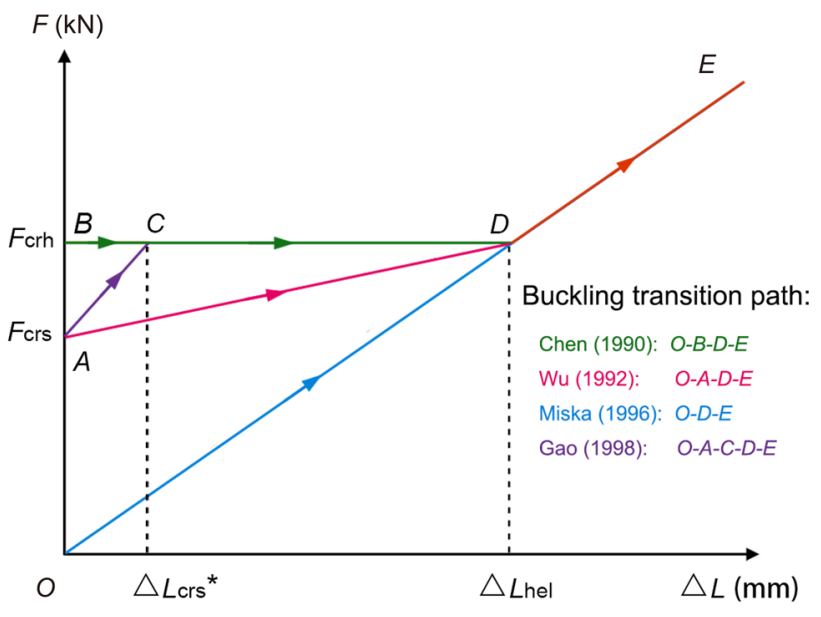

Fig. 2 The relationships between the axial force $(F)$ and axial compressive displacement $(\Delta L)$ in the loading process $\left(F_{\text {crs }}\right.$ is the critical sinusoidal buckling load, $F_{\text {crh }}$ is the critical helical buckling load, $\Delta L_{\mathrm{crs}}^{*}$ is the maximum axial compressive displacement at the end of the sinusoidal buckling stage, and $\Delta L_{\mathrm{crh}}$ is the minimum axial compressive displacement at the start of the helical buckling stage)

result. The upper limit means the minimum axial force causing helical buckling in the loading process, while the lower limit refers to the minimum axial force to keep the tubular string in the helical buckling stage for the unloading process. Mitchell (1997) obtained similar conclusions with the buckling differential equation. On the basis of previous studies, Gao et al. (2002) summarized the previous assumptions (Fig. 2) and considered that the axial force increases linearly in the sinusoidal buckling stage and then remains constant until the start of helical buckling based on experimental results.

In addition, the tubular string is always pushed on the inner surface of the wellbore whether in the sinusoidal or helical buckling stage. That is to say, the upper limit of the sinusoidal buckling is achieved when the contact force at the wellbore bottom is zero and the lower limit of the helical buckling is achieved when the contact force at the wellbore top is zero. Gao et al. (1998) calculated the critical buckling loads and found that these two limits are rather close to each other.

The differences among the results from different researchers mainly arise from two aspects. Firstly, previous buckling solutions are only approximate results with simplified assumptions. The accurate buckling solutions under sinusoidal buckling and helical buckling stages have not been obtained with the buckling differential equation and energy method. Secondly, a comprehensive description of the transition from the sinusoidal buckling to helical buckling has not been proposed due to the significant difference between these two buckling modes. The critical point between the sinusoidal buckling and helical buckling stages is usually assumed in theoretical analyses, but no 
Table 2 The critical axial forces for different buckling modes

\begin{tabular}{llll}
\hline Researchers & Sinusoidal buckling $\left(F / F_{\text {crs }}\right)$ & Sinusoidal or helical buckling $\left(F / F_{\text {crs }}\right)$ & Helical buckling $\left(F / F_{\text {crs }}\right)$ \\
\hline Chen et al. (1990) & {$[1, \sqrt{2}]$} & $/$ & {$[\sqrt{2}, \infty]$} \\
Wu (1992) & {$[1,2 \sqrt{2}-1]$} & $/$ & {$[2 \sqrt{2}-1, \infty]$} \\
Miska et al. (1996) & {$[1,1.875]$} & {$[1.875,2 \sqrt{2}]$} & {$[2 \sqrt{2}, \infty]$} \\
Cunha (1995), Mitchell (1997) & {$[1, \sqrt{2}]$} & {$[\sqrt{2}, 2 \sqrt{2}]$} & {$[2 \sqrt{2}, \infty]$} \\
Gao et al. (1998) & {$[1,1.401]$} & $/$ & {$[1.401, \infty]$} \\
\hline
\end{tabular}

distinct dividing point is found in experiments. Therefore, sophisticated description of the buckling state transition and accurate buckling solutions under these two buckling modes still needs an in-depth research.

Previous studies assumed the radial deflection of the tubular string was fixed on the borehole wall and derived the pitch-force relationship (Eq. (10)) with the energy method (Chen et al. 1990; Miska et al. 1996). Cheatham (1984) removed the radial constraint from the wellbore in the energy method and proposed another new pitch-force relationship in the helical buckling stage:

$F=\frac{4 \pi^{2} E I}{p^{2}}$.

Cheatham pointed out that Eqs. (10) and (14) are, respectively, applicable for the loading and unloading processes. In the loading process, the pitch of the helix is variable but the tubular string is constrained by the wellbore. However, in the unloading process, the tubular string tends to lose contact with the wellbore but the pitch of the helix remains constant. Huang et al. (2015a) verified Cheatham's results from the view of the buckling differential equation and further pointed out that the contact force reaches its maximum value when Eq. (10) is satisfied and its minimum value when Eq. (14) is satisfied.

Gao et al. (1998) pointed out that the tubular string weight has an turbulent effect on the helix configuration, and a more accurate buckling solution should be expressed by

$\theta=\frac{2 \pi}{p} z+A \sin \left(\frac{2 \pi}{p} z\right)$

The perturbation magnitude $A=-\frac{4}{5 \beta^{2}}$ is obtained by solving the buckling differential equation (Gao et al. 1998) and using the energy method (Gao 2006). Mitchell (2002a, b) used the Jacobi elliptic functions to solve the buckling differential equation and obtained the exact analytical helical buckling solution as follows:

$\theta=4 \sin ^{-1}\left[\operatorname{sn}\left(\sqrt{\frac{25+\sqrt{51} \beta}{50 \sqrt{51} \beta}} \cdot \frac{2 \pi z}{p}, \frac{50}{25+\sqrt{51} \beta}\right)\right]$.
Meanwhile, Mitchell (2002a,b) found another new buckling solution in which the tubular string buckles into a periodically reversing curve which oscillates with a large angular amplitude about the top of the wellbore rather than the bottom of the wellbore. Huang et al. (2015a) further proved that sinusoidal buckling and helical buckling are just two special periodical solutions of the buckling differential equation.

The effect of tubular string buckling on bending moment, axial compressive displacement, and contact force is also an important issue. Table 3 lists the values of these three factors in the sinusoidal buckling and helical buckling stages. The bending moment from sinusoidal buckling can be neglected, while bending moment from helical buckling is significant especially under a large axial force with a big radial clearance. Because the axial compressive displacement in the helical buckling stage is far larger than that in the sinusoidal buckling stage, the transition from sinusoidal buckling to helical buckling includes a section where the tubular string is continuously shortened with almost no increase in the axial compression. This phenomenon has been observed in buckling experiments (Salies 1994; Zou 2002) and now it has been introduced as an important assumption to calculate the critical helical buckling loads.

The effect of the additional contact force from sinusoidal buckling is usually small for the length of the tubular string in the sinusoidal buckling stage is quite limited $\left(F_{\text {crs }} \leq F<F_{\text {crh }}\right)$. However, the contact force increases significantly in the helical buckling stage $\left(F \geq F_{\text {crh }}\right)$ due to the quadric relationship between the contact force and axial compressive load and it can seriously restrict the axial force transfer when the friction force effect is taken into consideration.

\subsection{Curved wellbore}

Experiments (McCann and Suryanarayana 1994; Salies 1994) have shown that the build wellbore curvature has a stabilizing effect on tubular string buckling. The tubular string may have been in "lock-up" or yielded while the tubular string does not enter the buckling state in the build section (Kyllingstad 1995). 
Table 3 Relevant parameters in the post sinusoidal and helical buckling stages

\begin{tabular}{|c|c|c|c|}
\hline Buckling mode & Maximum bending moment $(M)$ & Axial compressive displacement $(\Delta L / L)$ & Contact force $(N)$ \\
\hline Sinusoidal & $\begin{array}{l}0.6302 F^{0.08}\left(F-F_{\mathrm{crs}}\right)^{0.92} r_{\mathrm{c}} \\
\quad \text { (Mitchell 1999a) }\end{array}$ & $\begin{array}{l}-0.7285 \frac{r_{\mathrm{c}}^{2}}{4 E I} F^{0.08}\left(F-F_{\mathrm{crs}}\right)^{0.92} \\
\quad(\text { Mitchell 1999a) } \\
-0.0843 \frac{r_{\mathrm{c}}^{2} F}{4 E I} \text { (Liu 1999) }\end{array}$ & $\begin{array}{l}q \sin \alpha \quad \text { (Mitchell 1999a) } \\
q \sin \alpha+\frac{r F^{2}}{8 E I} \quad(\text { Wu 1995) }\end{array}$ \\
\hline Helical & $0.5 F r_{\mathrm{c}}$ & $-\frac{r_{\mathrm{c}}^{2} F}{4 E I}$ & $\begin{array}{l}\frac{r F^{2}}{4 E I}+q \sin \alpha \text { (Mitchell 1999a) } \\
\frac{r F^{2}}{4 E I} \text { (Liu 1999) }\end{array}$ \\
\hline
\end{tabular}

The first theoretical research into the critical buckling loads in a curved wellbore was to convert the buckling problem in a curved wellbore into the equivalent buckling problem in an inclined wellbore. Considering that the tubular weight component perpendicular to the wellbore axis is equal to the contact force in the unbuckling state in an inclined wellbore, the critical buckling load can be expressed by (He and Kyllingstad 1995).

$F_{\mathrm{cr}}=\beta \sqrt{\frac{4 E I \cdot N}{r_{\mathrm{c}}}}$

where $\beta=1$ for Paslay's sinusoidal buckling and $\beta=\sqrt{2}$ for the Chen's helical buckling. Here, Eq. (17) is extended to the curved wellbore case, and the buckling load can be obtained by substituting the following contact force into a build section:

$N=\frac{F_{\mathrm{cr}}}{R}+q \sin \alpha$,

where $R$ is the curvature radius of the wellbore, $q$ is the weight per unit length of the tubular string, and $\alpha$ is the inclination angle.

$\mathrm{Wu}$ and Juvkam-Wold (1995a) deduced the critical buckling loads in build and drop-off wellbore sections shown in Tables 4 and 5 with the energy method, in which the lateral component of tubular string weight and axial force was considered to do negative work. Wu's results show that the critical buckling loads in curved wellbores are usually larger than that in straight wellbores, except that the critical buckling loads become smaller in drop-off wellbores with small curvature. Later, Qui et al. (1998) obtained the critical buckling loads in which only the lateral component of tubular string weight was considered to do negative work and found that the sinusoidal buckling has become unstable before the tubular string enters the helical buckling stage. Kyllingstad (1995) pointed out that there is an overlapping section for two buckling states which acts as a barrier for buckling mode conversion. Mitchell (1999b) obtained Miska's critical sinusoidal buckling loads by both solving the buckling differential equation and using energy stability analysis, and resolved the conflict between the Miska and Wu's results. Mitchell (1999b) pointed out that the lateral tubular string weight which appears to be part of the contact force can be neglected in Wu's studies as no work is done by the contact force. Liu (1999) solved the buckling differential equation with the Galerkin method and derived the critical helical buckling loads in build and drop-off wellbore sections by letting the minimum contact force on the tubular string be 0 . Liu's results indicate that the up-limit value of the sinusoidal buckling is rather close to the critical helical buckling load.

Similar to the inclined wellbore case, the sinusoidal and helical buckling solutions of the tubular string in a curved wellbore can be expressed by $\theta=A \sin (\omega \cdot z)$ and $\theta=\frac{2 \pi}{p} z+B \sin \left(\frac{2 \pi}{p} z\right)$, in which the variable $z$ is referred to the arc-length of the wellbore axis. The relevant parameters are calculated by $A=\sqrt{\frac{8(1-\lambda)}{12-\lambda}}, p=\sqrt{\frac{F}{2 E I}}$ and $B=-\frac{1}{5} \lambda$, where $\lambda=\left(\frac{F}{q \sin \alpha R}+1\right) \cdot \frac{4 E I q \sin \alpha}{r_{\mathrm{c}}} / F^{2}$ (Liu 1999).

The previous studies are mainly focused on build and drop-off wellbore sections in the vertical inclination plane. However, previous bucking models may not be applicable for three-dimensional wellbores of which both the inclination and azimuth angles change simultaneously in complex-structure wells. Therefore, a tubular string buckling model for arbitrary wellbores is needed.

\section{Effect of other factors}

\subsection{Torque}

Miska and Cunha (1995) proposed the critical helical buckling torque for a tubular string without axial force,

$T_{\mathrm{crh}}=2.087 \sqrt[4]{\frac{(E I)^{3} q \sin \alpha}{r}}$,

and then the pitch of the helix is equal to

$p=\frac{8 E I \pi}{3 T}$. 
Table 4 Critical buckling loads for build-up wellbores

\begin{tabular}{|c|c|c|}
\hline Researchers & Critical sinusoidal buckling $\left(F_{\mathrm{crs}}\right)$ & Critical helical buckling $\left(F_{\mathrm{crh}}\right)$ \\
\hline He et al. (1995) & $\frac{2 E I}{R r_{\mathrm{c}}} \sqrt{1+\sqrt{1+\frac{R^{2} r_{\mathrm{c}} q \sin \alpha}{E I}}}$ & $\frac{4 E I}{R r_{\mathrm{c}}} \sqrt{1+\sqrt{1+\frac{R^{2} r_{\mathrm{c}} q \sin \alpha}{2 E I}}}$ \\
\hline Wu and Juvkam-Wold (1995a) & $\frac{4 E I}{R r_{\mathrm{c}}} \sqrt{1+\sqrt{1+\frac{R^{2} r_{\mathrm{c}} q \sin \alpha}{4 E I}}}$ & $\frac{12 E I}{R r_{\mathrm{c}}} \sqrt{1+\sqrt{1+\frac{R^{2} r_{\mathrm{c}} q \sin \alpha}{8 E I}}}$ \\
\hline Qui et al. (1998) & $\frac{2 E I}{R r_{\mathrm{c}}} \sqrt{1+\sqrt{1+\frac{R^{2} r_{\mathrm{c}} q \sin \alpha}{E I}}}, \frac{2.532 E I}{R r_{\mathrm{c}}} \sqrt{1+\sqrt{1+\frac{R^{2} r_{\mathrm{c}} q \sin \alpha}{3.52 E I}}}$ & $\frac{8 E I}{R r_{\mathrm{c}}} \sqrt{1+\sqrt{1+\frac{R^{2} r_{\mathrm{c}} q \sin \alpha}{2 E I}}}$ \\
\hline Liu (1999) & $\frac{2 E I}{R r_{\mathrm{c}}} \sqrt{1+\sqrt{1+\frac{R^{2} r_{\mathrm{c}} q \sin \alpha}{E I}}}$ & $\frac{3.77 E I}{R r_{\mathrm{c}}} \sqrt{1+\sqrt{1+\frac{0.53 R^{2} r_{\mathrm{c}} q \sin \alpha}{E I}}}$ \\
\hline
\end{tabular}

Table 5 Critical buckling loads for drop-off wellbores

\begin{tabular}{lll}
\hline Researchers & Critical sinusoidal buckling $\left(F_{\text {crs }}\right)$ & Critical helical buckling $\left(F_{\mathrm{crh}}\right)$ \\
\hline Wu and Juvkam-Wold (1995a) & $\frac{4 E I}{R r_{\mathrm{c}}} \sqrt{1+\sqrt{1-\frac{R^{2} r_{\mathrm{c}} q \sin \alpha}{4 E I}}}$ (large curvature) & $\frac{12 E I}{R r_{\mathrm{c}}} \sqrt{1+\sqrt{1-\frac{R^{2} r_{\mathrm{c}} q \sin \alpha}{8 E I}}}$ (large curvature) \\
& $\frac{4 E I}{R r_{\mathrm{c}}} \sqrt{-1+\sqrt{1+\frac{R^{2} r_{\mathrm{c}} q \sin \alpha}{4 E I}}}$ (small curvature) & $\frac{12 E I}{R r_{\mathrm{c}}} \sqrt{-1+\sqrt{1+\frac{R^{2} r_{\mathrm{c}} q \sin \alpha}{8 E I}}}$ (small curvature) \\
Liu (1999) & $\frac{2 E I}{R r_{\mathrm{c}}} \sqrt{1+\sqrt{1-\frac{R^{2} r_{\mathrm{c}} q \sin \alpha}{E I}}}$ & $\frac{3.77 E I}{R r_{\mathrm{c}}} \sqrt{1+\sqrt{1-\frac{0.53 R^{2} r_{\mathrm{c}} q \sin \alpha}{E I}}}$ \\
\hline
\end{tabular}

However, the tubular string usually has yielded before torque reaches the critical value Eq. (19).

The critical helical buckling conditions while considering the effects of axial force, torque, and tubular string weight are shown in Table 6. Miska and Cunha (1995) derived the critical helical buckling load and pitch of the helix with the energy method. Later, He et al. (1995) treated the torque as a perturbation and obtained the approximate results for Miska's model. Wu (1997) assumed that there is only one period of helix when the axial force reaches its critical value and derived the critical buckling loads with the energy method. Their studies simultaneously show that the torque decreases the critical helical buckling load and pitch but increases the contact force. However, the pitch of the helix may be increased if the direction of the helix is opposite to that of the applied torque and torque has been proved to have no effect on sinusoidal buckling (Gao 2006). Paslay's experimental studies (Paslay 1994) indicated that the effect of torque on the critical helical buckling load was limited usually no more than $10 \%$.

Not only does torque affect the helical buckling configuration, but also helical buckling can also induce torque in turn. If a tubular string without torque at initial state is compressed axially and the two ends of the tubular string are constrained with no relative rotation, the induced torque due to helical buckling is equal to (Mitchell 2004)
$T_{\mathrm{ind}}=-\frac{F r_{\mathrm{c}}^{2}}{2} \sqrt{\frac{F}{2 E I}}$

Mitchell (2004) pointed out that the induced torque may exceed the makeup torque for large radial clearance. Gao (2006) supplemented Mitchell's theory and referred to the induced torque as an incentive for the helix direction reversal observed in experiments (Salies 1994).

\subsection{Boundary conditions}

For a long pinned-pinned or clamped-clamped tubular string, the buckling configuration is divided into two parts: the transition section adjacent to the boundary condition and the full buckling section in the middle shown in Fig. 3 (Huang et al. 2015b). The transition section is further divided into suspended and perturbed buckling sections. For the suspended section, the tubular string loses contact with the wellbore due to the support of the boundary condition. For the full buckling section, the tubular string buckles into a sinusoidal or helical configuration. The perturbed buckling section, on which the tubular string is in continuous contact with the wellbore, is seen as the transition from no contact to full buckling section.

$\mathrm{Wu}$ and Juvkam-Wold (1995a) pointed out that if a tubular string has 3.5 or more pitches of helix, the transition section can be neglected. Gao and Miska (2009, 
Table 6 Relevant parameters for the helical buckling with torque

\begin{tabular}{|c|c|c|c|}
\hline Researchers & Critical helical buckling loads $\left(F_{\text {crh }}\right)$ & Pitch of helix $(p)$ & Contact force $(N)$ \\
\hline Miska and Cunha (1995) & $F_{\mathrm{crh}}=\frac{4 \pi^{2} E I}{p^{2}}+\frac{q \sin \alpha}{2 \pi^{2} r} p^{2}-\frac{2 \pi T}{p}$ & $p^{2}=\frac{8 \pi^{2} E I}{F} \frac{1}{\left(1+\frac{3 \pi T}{F p}\right)}$ & l \\
\hline He et al. (1995) & $F_{\mathrm{crh}}=2 \sqrt{\frac{2 E I q \sin \alpha}{r}}\left(1-0.42 T \sqrt[4]{\frac{r}{(E I)^{3} q \sin \alpha}}\right)$ & l & $\frac{r F^{2}}{4 E I}\left(1+\frac{T}{\sqrt{E I \cdot F / 2}}\right)$ \\
\hline $\mathrm{Wu}(1997)$ & $F_{\mathrm{crh}}=2 \sqrt{\frac{2 E I q \sin \alpha}{r}}\left(1-\frac{T p}{4 E I \pi}\right)$ & $p=\sqrt[4]{\frac{8 \pi^{4} r E I}{q}} \cdot \sqrt[4]{1-\frac{T p}{4 \pi E I}}$ & l \\
\hline Gao (2006) & l & $p^{2}=\frac{8 \pi^{2} E I}{F}\left[\sqrt{1+\frac{9 T^{2}}{32 E I \cdot F}} \pm \frac{3 \sqrt{2} T}{8 \sqrt{E I \cdot F}}\right]^{2}$ & l \\
\hline
\end{tabular}

2010a) proved that the effect of the boundary condition on the full buckling section becomes negligible for a long pipe with the dimensionless length $\left(\frac{q}{E I r}\right)^{\frac{1}{4}} \cdot L$ larger than $5 \pi$.

The length of the transition section for fixed and pinned ends from different researchers is shown in Table 7. Mitchell (1982) assumed the transition section only included one suspended section. In Mitchell's analysis, the suspended section is described by the beam-column solutions and the full buckling section is expressed as a helix. On the basis of Mitchell's work, Liu et al. (1999) considered that the perturbed buckling section which connects the suspended section and the full buckling section cannot be ignored. In Liu's analysis, the perturbed buckling section is depicted described by the buckling differential equation, and the results show that the angular displacement rate decreases in an exponential manner in the perturbed buckling section. It is proved that the shear contact force on the contact point is not 0 in Mitchell's model and the contact force on the perturbed helix section is negative in Liu's model. Sorenson and Cheatham (1986) assumed that the suspended section is depicted by two suspended beams between which the adjacent point is in contact with the wellbore. The end of the perturbed buckling section is defined where the angular displacement change rate is 0.999 of that in the full buckling section. Later, Mitchell (2005) made some improvements on the calculation efficiency of Sorenson's model. All studies indicate that the transition section is smaller than one pitch of helix, namely $\eta_{1}+\eta_{2}+\eta_{3}<2 \pi$.

Huang et al. (2015a) pointed out that previous studies mainly considered the effect of axial force but neglected the bending moment and lateral force on the boundary constraints. Huang et al. proposed a novel classification method for the boundary conditions: if the virtual work of the bending moment and lateral force is 0 , it is called the first category; otherwise the second category. It is shown that the boundary condition can also affect the full helical buckling section of a long tubular string under the second category case. Huang et al. (2015b) further verified that the boundary condition is closely related to the buckling configuration stability and found that the helical buckling direction may reverse abruptly when the boundary condition goes across some critical values.

\subsection{Friction force}

Friction force is considered to be a stability factor which inhibits the deviation of the tubular string away from its initial state. Experimental results also have indicated that friction force on the tubular string can delay the onset of the sinusoidal buckling (McCann and Suryanarayana 1994).

Mitchell (2007) pointed out that the initial buckling with friction is in the form of pipe rolling but not sliding. After the lateral rolling buckling increases to a certain amplitude,

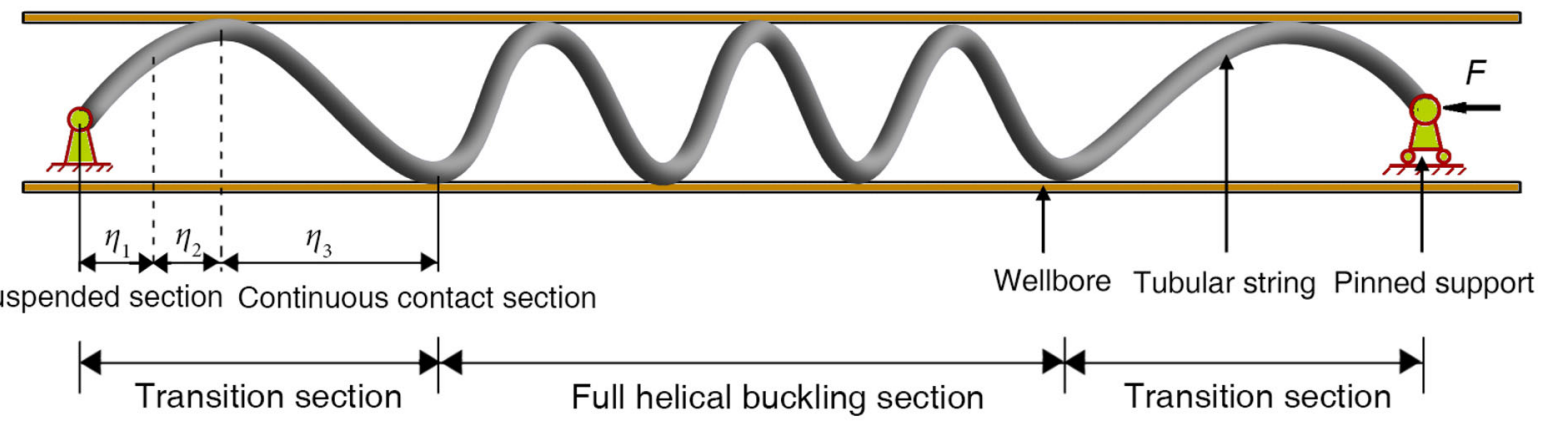

Fig. 3 Buckling configuration of a pinned-pinned tubular string in a horizontal wellbore. $\left(\eta_{1}, \eta_{2}\right.$, and $\eta_{3}$, respectively, represent the first suspended section, the second suspended section, and the continuous contact section) 
Table 7 Dimensionless lengths of the transition sections

\begin{tabular}{lllllll}
\hline Researchers & Boundary condition & $\eta_{1}$ & $\eta_{2}$ & $\eta_{1}+\eta_{2}$ & $\eta_{3}$ & $\eta_{1}+\eta_{2}+\eta_{3}$ \\
\hline Mitchell (1982) & Fixed end & 3.178 & 0 & 3.178 & 0 & 3.178 \\
Liu et al. (1999) & Fixed end & 2.718 & 0 & 2.718 & 1.211 & 3.929 \\
Sorenson and Cheatham ((1986), Mitchell (2005), Huang et al. (2015b) & Pinned end & 1.747 & 1.347 & 3.094 & 1.677 & 4.771 \\
& Fixed end & 2.700 & 0.903 & 3.603 & 1.846 & 5.449 \\
\hline
\end{tabular}

$\eta$ the dimensionless tubular string length $\sqrt{\frac{F}{2 E I}} \cdot L$

it converts to the sliding buckling form. Then the critical buckling load is calculated by

$\beta_{\mathrm{crs}}=1+\frac{G J}{r_{\mathrm{p}}^{2}} \sqrt{\frac{r_{\mathrm{c}}}{4 E I q}}$,

where $G J$ is the torsional stiffness of the tubular string. Gao and Miska (2010a) deduced the critical axial forces for sinusoidal buckling and helical buckling in a horizontal wellbore considering the sliding friction force with the energy method:

$\beta_{\mathrm{crs}} \approx 1+1.233 \mu^{\frac{2}{3}}$

$\beta_{\mathrm{crh}} \approx \sqrt{2}\left(1+\frac{\left(30+7 \pi^{2}\right) \mu}{30 \pi}\right)$.

Note that only the first order approximation of $\mu$ is retained in Eq. (23). Gao's theoretical results are proved to be consistent with the results from later experiments.

Su et al. (2013) solve the tubular string buckling equation with the friction effect using Fourier series. The results show that the tubular string can tolerate substantial perturbation in a no-buckling state.

After the buckling is initiated, the axial friction force becomes dominant and then causes a rapid decrease in axial force transfer or even "lock up" (Kuru et al. 1999). Mitchell (1986) obtained the axial force distribution in the tubular string slack off process in vertical wellbores shown in Table 8, in which the tubular string below the neutral point is considered to stay in helical buckling. Later, Mitchell (1996) applied the friction force in the axial displacement-based governing equation and solved the axial force transfer with a finite element method. Wu and Juvkam-Wold (1995b) studied the axial force transfer on the sinusoidal and helical buckling sections in vertical and horizontal wellbores. The results show that the axial force on the helical buckling section in vertical wellbores increases in a hyperbolic tangent function with respect to the well depth and approaches the limit value of $\sqrt{\frac{4 E I q}{\mu r_{\mathrm{c}}}}$ with an increase in well depth. The axial force on the helical buckling section in horizontal wellbores decreases in a negative tangent function with respect to the well length and the maximum extending length on the helical buckling section in a horizontal wellbore is $L=\frac{\pi}{\mu} \sqrt{\frac{E I}{q r_{c}}}$. Gao (2006) pointed out that $\mathrm{Wu}$ 's tubular string buckling analysis was based on the non-friction case and further proposed a coupled model of buckling, contact force, and axial force. The coupled model is given in the form of the buckling differential equation with the sliding friction force. In Gao's model, the lateral component of friction force is dominant at the instant of lateral buckling, while the axial component of the friction force becomes dominant at the helical buckling stage. The differential equations are solved with the Galerkin method and the multiple-scale method, and the results show that buckling initiation is delayed a lot due to the friction force. Gao and Miska (2010a) re-built Liu's buckling differential equation with the energy method and calculated the axial force transfer in horizontal wellbores on the basis of the critical buckling loads Eq. (23). Gao's results indicate that the maximum extending length on the helical buckling section in a horizontal wellbore is $\frac{4 E I}{\mu r_{\mathrm{c}} F_{\mathrm{crh}}}$.

One important method for improving the axial force transfer is rotating the tubular string. With rotation, the axial friction force can be dramatically decreased by converting the direction of the friction force from the axial direction to the rotational direction. Meanwhile, rotation also affects the tubular string buckling behavior. Menand et al. $(2008,2009)$ studied the effect of friction force and rotation on tubular string buckling with ABIS software and experiments, which indicates that rotation can reduce about $50 \%$ of the critical helical buckling load from a non-rotating case. Gao and Miska (2010b) deduced the dynamic buckling equation of a rotating tubular string without friction and solved it with a perturbation method. The results show that there are two kinds of snaking motion: the first one is that the tubular string moves up and down about the static buckling configuration, while the other is the tubular string moves from one side to the other side of the wellbore periodically. Both theoretical and experimental results indicate that rotation does not affect the critical buckling load. Hydraulic vibration is another way to improve the axial force transfer and the "lock up" phenomenon caused by the combined effects of friction force 
Table 8 Axial force transfer in vertical and horizontal wellbores

\begin{tabular}{|c|c|c|}
\hline & Sinusoidal bucking & Helical bucking \\
\hline Vertical wellbore & l & $\begin{array}{l}F=\sqrt{\frac{4 E I q}{\mu r_{\mathrm{c}}}} \tanh \left(z \sqrt{\frac{\mu q r_{\mathrm{c}}}{4 E I}}+c\right) \quad(\mathrm{Wu} \text { and } \\
\text { Juvkam-Wold 1995b; Mitchell 1986) }\end{array}$ \\
\hline Horizontal wellbore & 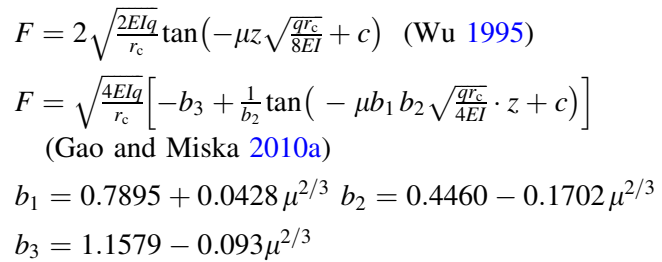 & $\begin{array}{l}F=\sqrt{\frac{4 E I q}{r_{\mathrm{c}}}} \tan \left(-\mu z \sqrt{\frac{q r_{\mathrm{c}}}{4 E I}}+c\right) \quad(\text { Wu and Juvkam-Wold 1995b) } \\
F=F_{\text {crh }} \frac{1}{1-\frac{\mu r_{\mathrm{c} F} F_{\mathrm{crh}}}{4 E I} z}(\text { Gao and Miska 2010a) }\end{array}$ \\
\hline
\end{tabular}

and helical buckling can be overcome through tubular string vibration (Barakat et al. 2007). Some researchers also believed that the connectors on the tubular string can inhibit the buckling initiation and reduce the friction force on the tubular string. The effects of connectors on tubular string buckling are discussed below.

\subsection{Connectors}

Connectors distribute discretely along the tubular string and the diameters of connectors are larger than that of the tubular string body. Therefore, there exist three contact cases between the tubular string and the wellbore: no contact, point contact, and wrap contact. No contact means that the tubular string suspends between connectors and does not touch the inner surface of the wellbore, point contact means that the tubular string touches the wellbore at a single point, and wrap contact means that a segment of the tubular string is in continuous contact with the wellbore. In addition, there are three buckling states: nonbuckling, sinusoidal buckling, and helical buckling. Huang et al. (2015c) pointed out that there are 9 deflection states and 12 transition conditions by the combination of three contact cases and three buckling states shown in Fig. 4. Generally speaking, a tubular string constrained in a straight wellbore goes through no contact, point contact to wrap contact for the contact states and non-buckling, sinusoidal buckling to helical buckling for the buckling states. However, the combination of connectors, tubular string buckling and other factors, such as wellbore configuration and tubular string gravity, is a complex problem.

In Fig. 4, "C" represents critical condition, "N," "P," and "W," respectively, denote no contact, point contact, and wrap contact, "I," "S," and "H," respectively, represent initial non-buckling, sinusoidal buckling, and helical buckling. For example, "Non-buckling \& No contact" means the initial non-buckling state under a no contact case, "C $\mathrm{C}_{\mathrm{NP} \_\mathrm{I}}$ " means the critical condition between no contact and point contact in the non-buckling state, and
"C $\mathrm{C}_{\text {IS_N }}$ " means the critical condition from initial nonbuckling to sinusoidal buckling under no contact state.

Lubinski (1977) studied the two-dimensional deflection of a weightless tubular string with axial tension in a curved wellbore and obtained the bending moment magnification due to the existence of connectors in the no contact, point contact, and wrap contact cases. Later, Paslay and Cernocky (1991) extended Lubinski's work to the axial compression case. The results show that the local bending curvature with connectors is larger than the wellbore curvature. Therefore, the bending moment magnification should be taken into consideration for the tubular string design. On the basis of Paslay's work, Huang et al. (2015c) further considered the effect of tubular string weight and assumed that the wellbore curvature is equivalent to an additional tubular string weight. The results show that the tubular string weight and wellbore curvature affect the critical transition conditions between different contact cases a lot. All these studies focus only on the two-dimensional lateral deflection situations.

Mitchell (2003a) studied the three-dimensional sinusoidal buckling problem of a tubular string constrained in a horizontal wellbore and gave the buckling solutions for the no contact case. According to Mitchell, the connector/ wellbore radial clearance $r_{\mathrm{c}}$ should be used in the critical sinusoidal buckling expression instead of the tubular string body/wellbore radial clearance $r_{\mathrm{b}}$ :

$F_{\mathrm{crs}}=1.991 \sqrt{\frac{E I q}{r_{\mathrm{c}}}} \approx 2 \sqrt{\frac{E I q}{r_{\mathrm{c}}}}$.

From Eq. (24), we can see that the critical buckling load can be improved to $\sqrt{r_{\mathrm{b}} / r_{\mathrm{c}}}$ times of that under no connector case. Later, Mitchell (2003b) extended his work to the sinusoidal buckling problem in a curved wellbore. Mitchell (2000) and Mitchell and Stefan (2006) further studied the helical buckling of a tubular string in a vertical wellbore for the no contact case. The results show that the tubular string approximately buckles helically when the axial compression is low while the effect of connectors on bending stress 


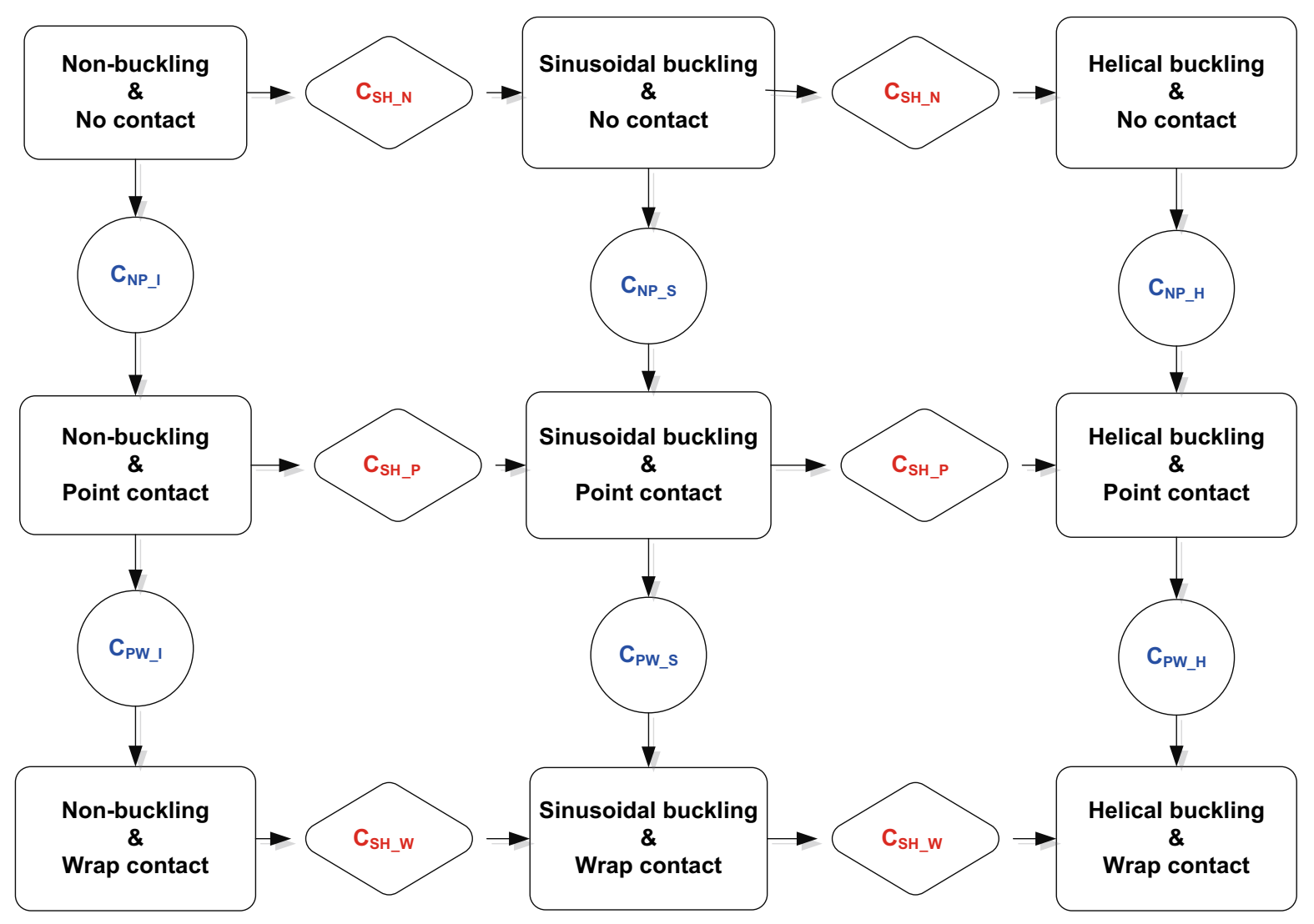

Fig. 4 Phase diagram of deflection states and critical conditions

becomes significant when the axial compression is high. Mitchell's results are verified by Duman's experiments (Duman et al. 2001, 2003) which show that connectors have no effect on the critical sinusoidal buckling load but increase the critical helical buckling load by $20 \%$.

Gao et al. (2012) studied the critical sinusoidal buckling load for a initially straight tubular string in no contact, point contact, and wrap contact cases. The results show that both the length between two adjacent connectors and the radial clearance difference between the tubular string body and connector affect the critical buckling loads a lot. With a decrease in the length between two adjacent connectors, the effective radial clearance approaches the connector radial clearance. When the length between two adjacent connectors reaches the critical value where the tubular string is just in point contact with the wellbore, the critical buckling load achieves its minimum value. Gao's results were proved to be in good agreement with numerical calculation (Daily et al. 2013; Hajianmaleki and Daily 2014).

On the basis of Mitchell's and Gao's studies, Huang and Gao (2014a, b, 2015) presented the complete phase diagram of the tubular string deflection states and studied the sinusoidal buckling and helical buckling problems for a tubular string constrained in horizontal and curved wellbores. Huang's studies indicate that the effect of connectors on the tubular string buckling behavior is significant and reaches a maximum value under the critical condition from no contact to point contact cases.

Previous results indicate that connectors can delay the buckling initiation, reduce the contact force between tubular string and wellbore, and improve the axial force transfer on the tubular string. Therefore, a reasonable optimization of connector parameters may greatly improve the tubular string extension limit in long horizontal-section and extended-reach wells. For practical application, theoretical results about the effect of connectors on tubular string buckling and contact force should be obtained first.

\section{Conclusions}

In this article, our aim is to introduce three main research methods in down-hole tubular string buckling, summarize the effects of relevant factors on the critical buckling loads and post-buckling behavior, and draw a picture for future research in this field. Previous studies built the basic 
knowledge framework of down-hole tubular string buckling theory in which three issues are studied in detail: (1) the description of the transition between different buckling modes and the corresponding critical buckling loads; (2) the buckling behavior including the deflection curve, bending moment, and contact force under different bucking modes; (3) the effects of relevant factors such as wellbore configuration, torque, and boundary conditions. It is indicated that down-hole tubular string buckling is a complex problem because of the involvement of instability, nonlinearity, multiple factors etc. Future research on downhole tubular string buckling should still be conducted from two aspects: (1) a more sophisticated and more accurate description of the critical buckling conditions and postbuckling behavior, such as the quantitative description of the full path for the buckling mode transition in a vertical wellbore and an arbitrary three-dimensional wellbore; (2) the combination of as many factors as possible, such as the buckling behavior of a tubular string with connectors under the action of friction force in a three-dimensional wellbore. To achieve the above objects, the three research methods should be combined to solve the down-hole tubular string buckling problems and an efficient calculation program to solve the generated nonlinear algebraic equations should be proposed. In addition, the previous studies mainly focused on the mechanism of the down-hole tubular string buckling but neglected the active control of the tubular string buckling behaviors, which provides an important guidance for improving the extending limit of the tubular string in well engineering. Therefore, the achievement of active control is also a prominent research direction in the downhole tubular buckling.

Acknowledgments The authors gratefully acknowledge the financial support from the Natural Science Foundation of China (NSFC, 51221003, U1262201) and the Science Foundation of China University of Petroleum, Beijing (No. 00000). This research is also supported by other projects (Grant Numbers: 2014A-4214, 2013AA064803, 2011ZX05009-005).

Open Access This article is distributed under the terms of the Creative Commons Attribution 4.0 International License (http://creativecommons.org/licenses/by/4.0/), which permits unrestricted use, distribution, and reproduction in any medium, provided you give appropriate credit to the original author(s) and the source, provide a link to the Creative Commons license, and indicate if changes were made.

\section{References}

Barakat ER, Miska SZ, Yu M, et al. The effect of hydraulic vibrations on initiation of buckling and axial force transfer for helically buckled pipes at simulated horizontal wellbore conditions. SPE/ IADC drilling conference, 20-22 February Amsterdam, 2007. http://dx.doi.org/10.2118/105123-MS.
Cheatham JB Jr. Helical postbuckling configuration of a weightless column under the action of $m$ axial load. Soc Pet Eng J. 1984; 24(4):467-72.

Chen Y, Lin Y, Cheatham JB. Tubing and casing buckling in horizontal wells (includes associated papers 21257 and 21308). SPE J Pet Technol. 1990;42(2):140-91.

Cunha JCDS. Buckling behavior of tubulars in oil and gas wells: a theoretical and experimental study with emphasis on the torque effect. Ph.D. dissertation. The University of Tulsa. 1995.

Daily JS, Ring L, Hajianmaleki M, et al. Critical buckling load assessment of drill strings in different wellbores using the explicit finite element method. SPE offshore europe oil and gas conference and exhibition, Aberdeen, 2013. http://dx.doi.org/10. 2118/166592-MS.

Dawson R. Drill pipe buckling in inclined holes. J Pet Technol. 1984;36(10):1734-8.

Dellinger T, Gravley W, Walraven JE. Preventing buckling in drill string. US patent: 4384483. 1983.

Duman OB, Miska S, Kuru E. Effect of tool joints on contact force and axial force transfer in horizontal wellbores. SPE/IADC middle east drilling technology conference, 2001. http://dx.doi. org/10.2118/72278-MS.

Duman OB, Miska S, Kuru E. Effect of tool joints on contact force and axial-force transfer in horizontal wellbores. SPE Drill Complet. 2003;18(03):267-74.

Gao GH, Li Q, Zhang J. Buckling analysis of pipe string in a vertical borehole. J Xi' an Pet Inst. 1996;11(1):33-5 (in Chinese).

Gao GH, Miska SZ. Effects of boundary conditions and friction on static buckling of pipe in a horizontal well. SPE J. 2009;14(4): 782-96.

Gao GH, Miska SZ. Effects of friction on post-buckling behavior and axial load transfer in a horizontal well. SPE J. 2010a;15(4): 1104-18.

Gao GH, Miska SZ. Dynamic buckling and snaking motion of rotating drilling pipe in a horizontal well. SPE J. 2010b;15(3): 867-77.

Gao GH, Di Q, Miska SZ, et al. Stability analysis of pipe with connectors in horizontal wells. SPE J. 2012;17(3):931-41.

Gao DL. Down-hole tubular mechanics and its applications. Dongying: China University of Petroleum Press; 2006 (in Chinese).

Gao DL, Liu FW, Xu BY. An analysis of helical buckling of long tubulars in horizontal wells. SPE international oil and gas conference and exhibition in China, 2-6 November Beijing, 1998. http://dx.doi.org/10.2118/50931-MS

Gao DL, Lui FW, Xu BY. Buckling behavior of pipes in oil \& gas wells. Prog Nat Sci. 2002;12(2):126-30 (in Chinese).

Gao DL, Liu FW. The post-buckling behavior of a tubular string in an inclined wellbore. Comput Model Eng Sci. 2013;90(1):17-36.

Hajianmaleki M, Daily JS. Critical-buckling-load assessment of drillstrings in different wellbores by use of the explicit finiteelement method. SPE Drill Complet. 2014;29(2):256-64.

He X, Kyllingstad A. Helical buckling and lock-up conditions for coiled tubing in curved wells. SPE Drill Complet. 1995;10(1): $10-5$.

He X, Halsey GW, Kyllingstad A. Interactions between torque and helical buckling in drilling. SPE annual technical conference and exhibition, 22-25 October, Dallas, 1995. http://dx.doi.org/10. 2118/166592-MS.

Huang WJ, Gao DL. Sinusoidal buckling of a thin rod with connectors constrained in a cylinder. J Natl Gas Sci Eng. 2014a;18:237-46.

Huang WJ, Gao DL. Helical buckling of a thin rod with connectors constrained in a cylinder. Int J Mech Sci. 2014b;84:189-98.

Huang WJ, Gao DL. Helical buckling of a thin rod with connectors constrained in a torus. Int J Mech Sci. 2015;98:14-28. 
Huang WJ, Gao DL, Liu FW. Buckling analysis of tubular strings in horizontal wells. SPE J. 2015a;20(2):405-16. http://dx.doi.org/ 10.2118/171551-PA.

Huang WJ, Gao DL, Wei SL. Boundary condition: a key factor in tubular string buckling. SPE J. 2015b. Preprint. http://dx.doi.org/ 10.2118/174087-PA.

Huang WJ, Gao DL, Wei SL. Local mechanical model of down-hole tubular strings constrained in curved wellbores. J Pet Sci Eng. 2015c;192:233-42.

Kuru E, Martinez A, Miska S, et al. The buckling behavior of pipes and its influence on the axial force transfer in directional wells. SPE/IADC drilling conference, 9-11 March, Amsterdam, 1999. http://dx.doi.org/10.2118/52840-MS

Kyllingstad A. Buckling of tubular strings in curved wells. J Pet Sci Eng. 1995;12(3):209-18.

Liu FW, Xu BY, Gao DL. Packer effect analysis of helical buckling of well tubing. J Tsinghua Univ. 1999;39(8):105-8 (in Chinese).

Liu FW. Post-buckling behaviors of tubulars within circular cylinders. Ph.D. dissertation. Beijing: Tsinghua University. 1999. (in Chinese).

Lubinski A. A study of the buckling of rotary drilling strings. Am Pet Inst. 1950;224(1):123-65.

Lubinski A. Fatigue of range 3 drill pipe. Revue de l'Inst Français du Pétrole. 1977;32(2):209-32.

Lubinski A, Althouse WS. Helical buckling of tubing sealed in packers. J Pet Technol. 1962;14(6):655-70.

McCann RC, Suryanarayana PVR. Experimental study of curvature and frictional effects on buckling. Offshore technology conference, 5/2/1994, Houston, 1994. http://dx.doi.org/10.4043/7568MS.

Menand S, Sellami H, Akowanou J, et al. How drillstring rotation affects critical buckling load? IADC/SPE drilling conference, 4-6 March, Orlando, 2008. http://dx.doi.org/10.2118/112571MS.

Menand S, Sellami H, Tijani M, et al. Buckling of tubulars in simulated field conditions. SPE Drill Complet. 2009;24(2):276-85.

Miska S, Cunha JC. An analysis of helical buckling of tubulars subjected to axial and torsional loading in inclined wellbores. SPE production operations symposium, 2-4 April, Oklahoma City, 1995. http://dx.doi.org/10.2118/29460-MS.

Miska S, Qiu W, Volk L, et al. An improved analysis of axial force along coiled tubing in inclined/horizontal wellbores. International conference on horizontal well technology, 18-20 November, Calgary, 1996. http://dx.doi.org/10.2118/37056-MS.

Mitchell RF. Buckling behavior of well tubing: the Packer effect. Soc Pet Eng J. 1982;22(5):616-24.

Mitchell RF. Simple frictional analysis of helical buckling of tubing. SPE Drill Eng. 1986;1(6):457-65.

Mitchell RF. New concepts for helical buckling. SPE Drill Eng. 1988;3(3):303-10.

Mitchell RF. Comprehensive analysis of buckling with friction. SPE Drill Complet. 1996;11(3):178-84.

Mitchell RF. Effects of well deviation on helical buckling. SPE Drill Complet. 1997;12(1):63-70.

Mitchell RF. Buckling analysis in deviated wells: a practical method. SPE Drill Complet. 1999a;14(1):11-20.

Mitchell RF. A buckling criterion for constant-curvature wellbores. SPE J. 1999b;4(4):349-52.

Mitchell RF. Helical buckling of pipe with connectors in vertical wells. SPE Dril Complet. 2000;15(3):162-6.
Mitchell RF. Exact analytic solutions for pipe buckling in vertical and horizontal wells. SPE J. 2002a;7(4):373-90.

Mitchell RF. New buckling solutions for extended reach wells. IADC/ SPE drilling conference, 26-28 February, Dallas, 2002b. http:// dx.doi.org/10.2118/74566-MS.

Mitchell RF. Lateral buckling of pipe with connectors in horizontal wells. SPE J. 2003a;8(2):124-37.

Mitchell RF. Lateral buckling of pipe with connectors in curved wellbores. SPE Drill Complet. 2003b;18(1):22-32.

Mitchell RF. The twist and shear of helically buckled pipe. SPE Drill Complet. 2004;19(1):20-8.

Mitchell RF. The pitch of helically buckled pipe. SPE/IADC drilling conference, 23-25 February, Amsterdam, 2005. http://dx.doi. org/10.2118/74566-MS.

Mitchell RF. The effect of friction on initial buckling of tubing and flowlines. SPE Drill Complet. 2007;22(2):112-8.

Mitchell RF, Stefan ZM. Helical buckling of pipe with connectors and torque. SPE Drill Complet. 2006;21(2):108-15.

Paslay PR. Stress analysis of drillstrings. University of Tulsa Centennial Petroleum engineering symposium, 29-31 August, Tulsa, 1994. http://dx.doi.org/10.2118/27976-MS.

Paslay PR, Bogy DB. The stability of a circular rod laterally constrained to be in contact with an inclined circular cylinder. J Appl Mech. 1964;31(4):605-10.

Paslay PR, Cernocky EP. Bending stress magnification in constant curvature doglegs with impact on drillstring and casing. SPE annual technical conference and exhibition, 6-9 October, Dallas, 1991. http://dx.doi.org/10.2118/22547-MS.

Qui W, Miska S, Volk L. Drill pipe/coiled tubing buckling analysis in a hole of constant curvature. SPE Permian Basin oil and gas recovery conference, 23-26 March, 1998. http://dx.doi.org/10. 2118/39795-MS.

Salies JB. Experimental study and mathematical modeling of helical buckling of tubulars in inclined wellbores. Ph.D. dissertation. The University of Tulsa. 1994.

Sorenson KG, Cheatham JJB. Post-buckling behavior of a circular rod constrained within a circular cylinder. J Appl Mech. 1986;53(4): 929-34.

Su T, Wicks N, Pabon J, et al. Mechanism by which a frictionally confined rod loses stability under initial velocity and position perturbations. Int J Solids Struct. 2013;50(14-15):2468-76.

Timoshenko SP, Gere JM. Theory of elastic stability. 2nd ed. New York: Tata McGraw-Hill Education; 1963.

$\mathrm{Wu}$ J. Buckling behavior of pipes in directional and horizontal wells. Ph.D. dissertation. Texas: Texas A\&M University. 1992.

Wu J. Slack-off load transmission in horizontal and inclined wells. SPE production operations symposium, 2-4 April, Oklahoma City, 1995. http://dx.doi.org/10.2118/29496-MS.

Wu J, Juvkam-Wold HC. The effect of wellbore curvature on tubular buckling and lockup. J Energy Resour Technol. 1995a;117(3): 214-8.

Wu J, Juvkam-Wold HC. Coiled tubing buckling implication in drilling and completing horizontal wells. SPE Drill Complet. 1995b;10(01):16-21.

Wu J. Torsional load effect on drill-string buckling. SPE production operations symposium, 9-11 March, Oklahoma City, 1997. http://dx.doi.org/10.2118/37477-MS.

Zou HH. Study of tubular string buckling in inclined straight wellbores. MS thesis. Beijing: China University of Petroleum. 2002. (in Chinese). 